\title{
Is the Surgical Margin in Gastrointestinal Stromal Tumors Different?
}

\author{
Piotr Rutkowski ${ }^{a} \quad$ Jacek Skoczylas ${ }^{b}$ Piotr Wisniewskia \\ a Department of Soft Tissue/Bone Sarcoma and Melanoma, Maria Sklodowska-Curie Institute - Oncology Center, Warsaw, Poland; \\ ${ }^{\mathrm{b}}$ Department of Pathology, Maria Sklodowska-Curie Institute - Oncology Center, Warsaw, Poland
}

\section{Keywords}

Gastrointestinal stromal tumor · Surgery · Pathology · Margin · Imatinib · Neodjuvant · Tumor perforation

\section{Summary}

Background: Radical surgical excision is the mainstay of therapy of primary, nonmetastatic gastrointestinal stromal tumors (GIST) and margin status after surgery is a significant prognostic factor. Methods and Results: The aim of this paper is to review principles in primary GIST surgery, i.e. differences between R0, R1, and R2 resection, to describe how surgical margin status and tumor intraperitoneal rupture influence the patients' outcome, and how this may be effected by neoadjuvant and adjuvant treatment in locally advanced tumors. A systematic search of literature published between 2000 and 2018 was performed regarding this topic. Conclusion: Correct interpretation of margin status after surgery can be affected by many factors during operation and preparation of tissue.

(c) 2018 S. Karger GmbH, Freiburg

\section{Introduction}

Gastrointestinal stromal tumors (GIST) comprise a heterogeneous group of mesenchymal tumors and the most common sarcomas of the gastrointestinal tract. Radical surgery is the treatment of choice for primary, resectable, localized GIST, but the majority of GISTs is associated with some risk of recurrence, and approximately $40-50 \%$ of patients relapse after potentially curative resections, mostly in the form of metastatic disease [1-3]. Understanding the molecular mechanisms of their pathogenesis demonstrated that a majority of GIST are associated with activating, somatic, mutually exclusive mutations of 2 genes, KIT and PDGFRA (plateletderived growth factor receptor-alpha), and an overexpression and activation of the oncoproteins KIT and PDGFR. Advances in the understanding of molecular pathogenesis of GIST have resulted in the development of a treatment modality which has become a model for targeted therapy in oncology. Imatinib mesylate has revolutionized the therapy of advanced GIST and was the first effective, worldwide approved nonsurgical treatment in inoperable and/ or metastatic cases, and currently in adjuvant therapy. The treatment of choice in primary, resectable, localized GIST is radical surgery with negative margins. However, the microscopic status of surgical margins is controversial and contrary to other sarcomas, GIST local recurrences occur rarely.

The main prognostic factors in primary GIST after resection comprise: tumor location, size, and mitotic index. Several risk stratification systems have been proposed in last 20 years. The most commonly used is the classification for risk assessment in gastric, duodenal, and intestinal GIST (National Comprehensive Cancer Network-American Forced Institute of Pathology (NCCNAFPI) $[1,4-7]$ which constituted the basis for the staging system of the American Joint Committee on Cancer (AJCC) $[8,9]$, and it reflects the fact that gastric GIST show a lower rate of aggressive behavior than jejunal and ileal GIST of comparable size and/or mitotic rate. Currently, on this basis, patients are divided into a very low/low-, intermediate- or high-risk group. However, further factors are still the matter of research that will improve the classification. There are some studies showing that the status of excision margins, perforation during surgery, and the presence of the KIT / PDGFR mutation may be important in estimating chances for local recurrence and also may be helpful in the case of decisions regarding neoadjuvant and adjuvant treatment. Recently, it was established that tumor rupture (spontaneous or iatrogenic) is an additional important risk factor strongly associated with the increased recurrence rates. In 2008, Joensuu [10] proposed another simpli-

\section{KARGER}

() 2018 S. Karger GmbH, Freiburg

Fax +497614520714
Prof. Dr. hab. n. med. Piotr Rutkowski Department of Soft Tissue/Bone Sarcoma and Melanoma Maria Sklodowska-Curie Institute - Oncology Center Roentgena 5, 02-781 Warsaw, Poland piotr.rutkowski@ coi.pl 


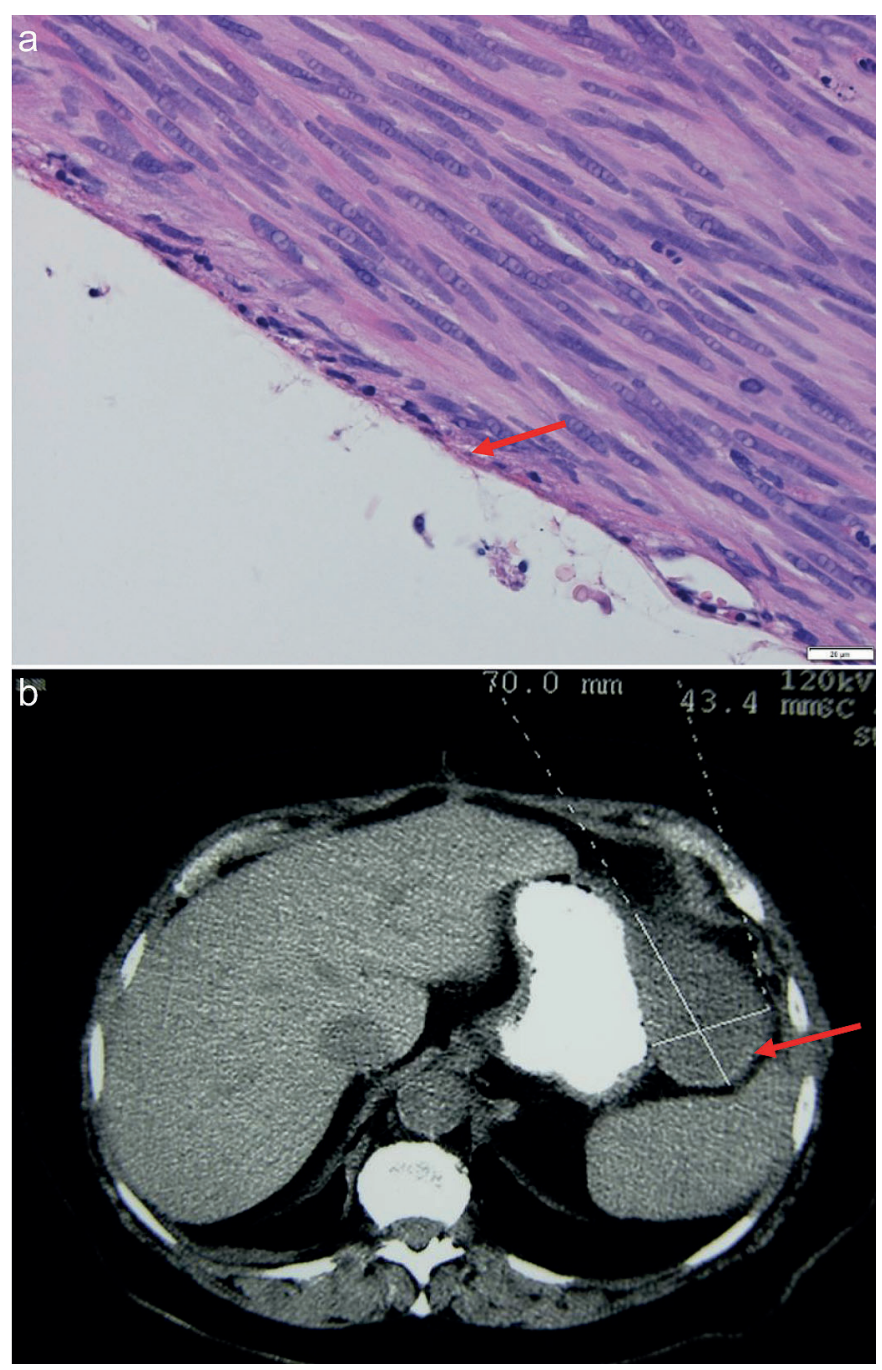

Fig. 1. Serous margin of gastrointestinal stromal tumor - microscopic photograph (HE 40x) and computed tomography imaging (arrow).

fied classification system based on 4 prognostic factors (tumor size, site, mitotic count), including the presence of tumor rupture [911]. It seems also rather obvious that patients with resectable primary GIST who undergo R0 resection have significantly longer survival that those after incomplete (especially macroscopic) resection $[2,12]$; however, this may be related to the primary characteristic of a more aggressive and advanced tumor than mechanistic effect of microscopic residual disease.

The aim of this review based on systematic search of published literature is to discuss the importance of achieving macroscopically and microscopically tumor-free margins in GIST and definition of margins, as well as the possible impact of perioperative therapy.

\section{Assessment of Primary GIST Margins}

The correct interpretation of the pathological margins after GIST resection may be challenging and should be performed by an experienced sarcoma pathologist. GIST may occur in all localiza-

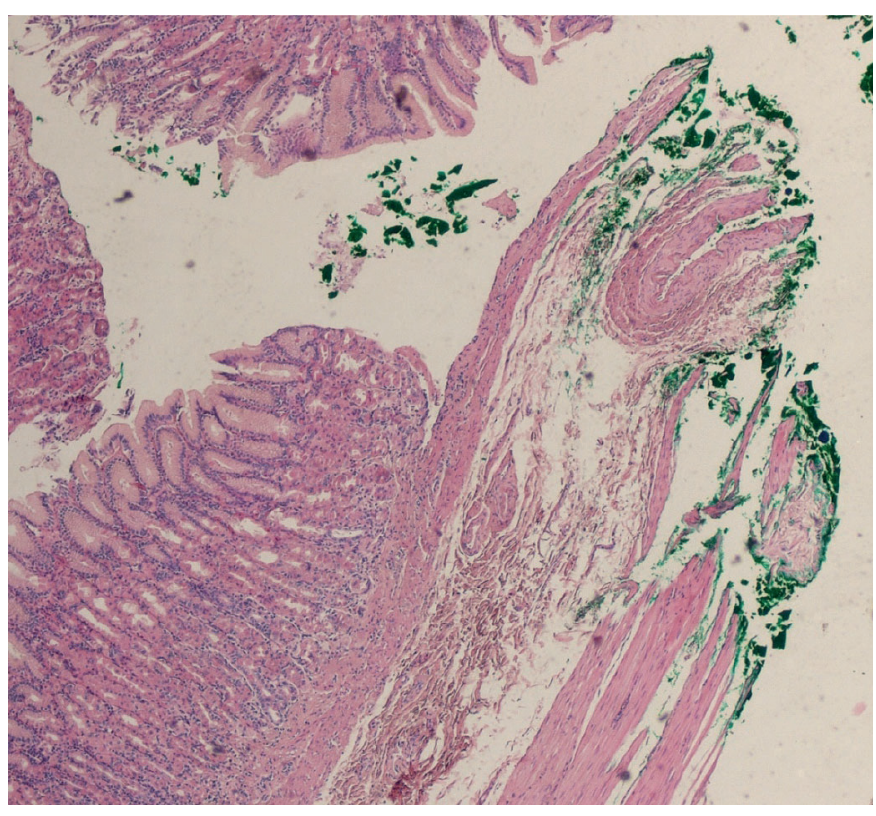

Fig. 2. Inked lateral margins of the mucosa of the stomach.

tions in the gastrointestinal tract. The first step is a proper orientation of the specimen, which should be well marked and described by the surgeon. The margin's evaluation can be affected by contraction of tumor, bowel/stomach wall as well as fixation of the specimen after resection and tissue preparation. The suspicion of microscopically positive $\mathrm{R} 1$ resection margin should be carefully evaluated, because it does not always mean incomplete resection due to false-positive assessment based on improper orientation of specimen, tissue contraction, or encapsulation after resection. It is necessary to record if there was a tumor rupture (to the peritoneal cavity) during the operation. To correctly interpret the microscopic image of the removed tumor and establish the margins of resection, it should be considered that GIST is a tumor growing under the mucosa [13], and mucosal margin from the lumen of the gastrointestinal tract is not clinically meaningful (as GIST may be often ulcerated). The margins of clinically importance are (fig. 1-3):

(1) from the peritoneal cavity side - the tumor pseudocapsule covered by one layer of serosa may constitute this margin and, if intact, it is a sufficient one, and this is a natural limit as you cannot achieve a wider margin here (fig. 4), if it is disrupted it implies the tumor rupture;

(2) lateral margins or proximal and distal resection margins of the stomach/intestine wall which are suggested to be at least $1 \mathrm{~cm}$. In this area, the width of the excision should be verified.

These margins determine whether a R0, R1, or R2 resection has been performed.

\section{Principles of GIST Surgery}

Surgery is the mainstay and the only potentially curative treatment for primary localized GIST. The recommended approach is R0 resection with wide margins of about $1-2 \mathrm{~cm}$ (fig. 4). Gentle 
Fig. 3. Schematic drawing of surgical margins

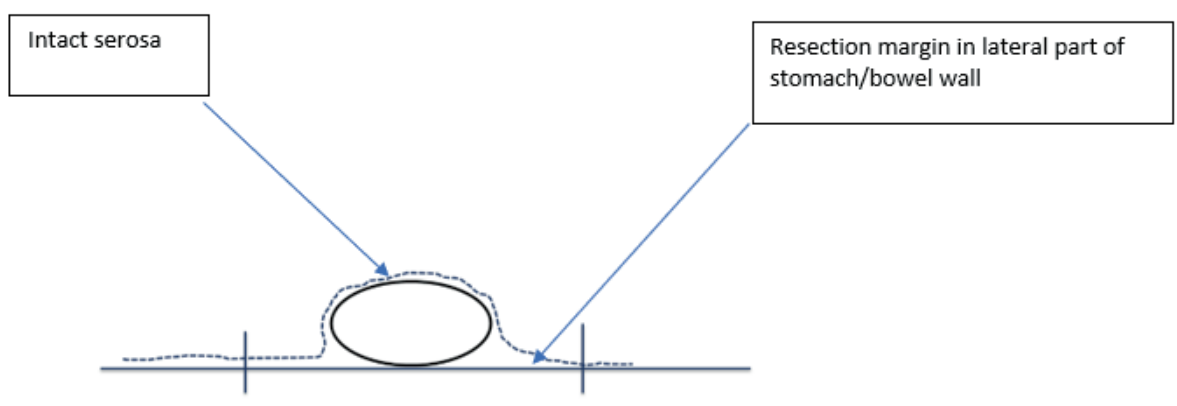

in transverse plane.

handling is also very important to avoid tumor rupture. Routine lymphadenectomy is not recommended unless there is no suspicion of intraoperative lymph node metastasis. Wide wedge-like excision is recommended, but in some cases, partial or complete gastrectomy may be necessary due to the location (pylorus or gastroesophageal junction) or size of the tumor, although several studies did not confirm any benefits of extended surgery for gastric GIST beyond a local excision [14]. Nondisruptive surgical techniques must be used in all cases of GIST, especially those with large cystic or necrotic components. Tumor enucleation is considered insufficient because it may leave tumor cells behind a pseudocapsule; it is also considered as tumor rupture [15]. Nishimura et al. [16] found $33 \%$ incidence of local or peritoneal recurrence in tumors which were incidentally enucleated during surgical resection.

In the case of initially advanced, marginally resectable tumors or with risk of mutilating surgery, the neoadjuvant imatinib should be considered, especially in high-risk patients to reduced extent of surgery and the risk of tumor rupture during operation. When GIST are adherent to contiguous organs, en-bloc resection of the tumor and adherent structures should be considered [17, 18].

\section{Laparoscopy/Endoscopy in the Treatment of GIST}

The currently widely discussed clinical problem is the use of minimally invasive laparoscopic and endoscopic surgery for the removal of primary GIST. There are many papers on the safety of laparoscopic resection; however, most often they refer only to gastric GIST. The achieved oncological results are comparable to open surgery [19-22]. Currently, laparoscopic resection is permissible in tumors below $10 \mathrm{~cm}$ in maximal diameter and when the risk of local recurrence is low even after R1 resection; however, the size limits of tumors are constantly shifted. In the case of laparoscopic treatment, similar rules apply as in the case of open surgery plus it is necessary to remember to be gentle during the operation (extra care while manipulating because GIST are soft and fragile) (fig. 5). Moreover, the tumor should be removed from the peritoneal cavity in an extraction bag to avoid contamination of the abdominal cavity with cancer cells (intraperitoneal seeding). If not, this immediately changes the patient's outcome and shifts the patient into a high-risk group. Tumor disruption must be avoided at all costs;
Fig. 4. Radically excised ulcerated gastric gastrointestinal stromal tumor with axial margins of stomach wall of $1-2 \mathrm{~cm}$.
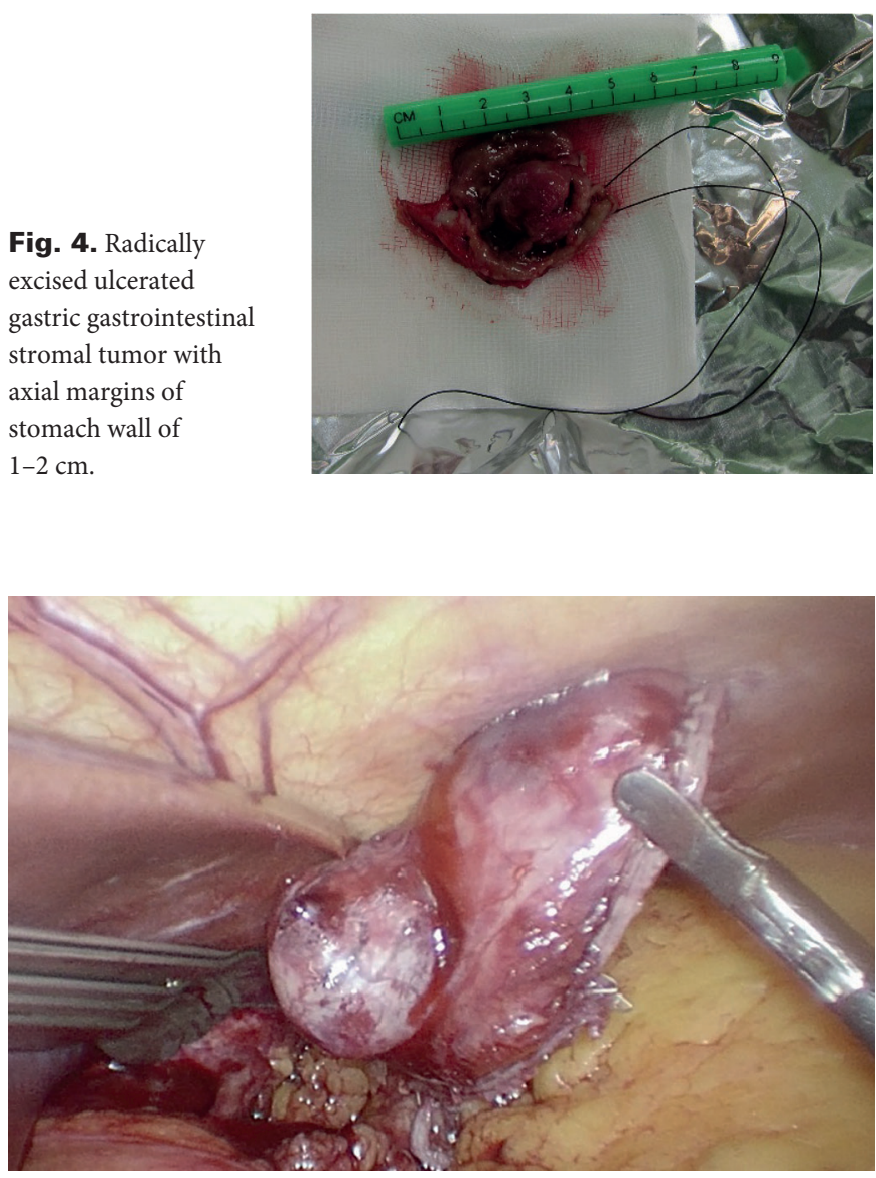

Fig. 5. Intraoperative photograph of laparoscopic gastrointestinal stromal tumor resection.

tumor enucleation leaves a tumor-seeded pseudocapsule behind and is considered insufficient.

In small (low-risk) GISTs, attempts are made to remove them endoscopically, however, often it is not possible to obtain a wide $\mathrm{R} 0$ resection but even in the case of $\mathrm{R} 1$ resection, the prognosis of patients is comparable. Moreover, only patients with small lowrisk well-defined tumors should be considered eligible for endoscopic GIST removal in one part. R1 resection is more frequent in the endoscopic resection but the recurrence rate in some studies is as low as $3 \%$ and is therefore not much different from surgical re- 
section [13, 23]. Joo et al. [23] reported an $\mathrm{R} 0$ resection rate of $25.6 \%$ in the endoscopy group, whereas it was $85.0 \%$ in the surgery group ( $\mathrm{p}<0.001$ ). In the endoscopy group, $50.0 \%$ of resected tumors belonged to a very low-risk group, whereas 35.0 and $30.0 \%$ belonged to the low-risk and high-risk surgery group $(\mathrm{p}<0.001)$, respectively. Nevertheless, with 45.5 -month follow-up, the recurrence rate was not significantly different between these 2 groups ( 2.2 vs. $5.0 \% ; \mathrm{p}=0.586$ ).

\section{Margins and Risk of Recurrence}

The impact of microscopic positivity on the patients' outcomes was not studied systematically and major series (table 1) show inconsistent data [2, 24-26]. It is currently doubtful that a positive macroscopic surgical margin status ( $\mathrm{R} 2$ resection) is associated with poor disease-specific survival in GIST [25-27]. Although in sarcoma surgery it is believed that achieving R0 resection is one of the most important factors predicting good prognosis, the ESMO guidelines state that 'when R0 surgery implies major functional sequelae, a preoperative medical treatment has not helped or cannot be exploited, the decision can be shared with patient to accept possible R1 margins' [14]. Microscopically positive margins are the most acceptable for low-risk lesions lacking the formal demonstration of an association of R1 surgery with poorer overall survival [28]. Several major published series in primary GIST analyzed only the term complete macroscopic resection $[12,27,29]$, whereas others focused on R0 resections [30-32] as the desired standard of care in the surgical treatment of GIST. Some studies showed that microscopic (positive or negative) surgical margin status has no influence on a patient's survival/tumor recurrence in GIST [12, 24, 27]. The published series including the assessment of microscopically positivity of margins are relatively small, and they included a high number of large and high-grade GIST, in which even complete resection does not seem to avoid tumor recurrence and shorter patient survival due to a natural course of disease. Other studies demonstrate that microscopically negative surgical margin status (R0 resection) has an important impact on the prognosis in GIST [2, 30, 31, 33, 34]. An analysis of 79 cases by a Swedish group reported that local/peritoneal recurrences were diagnosed in a significantly lower percentage of 2 out of 39 cases with wide margins (at least $2 \mathrm{~cm}$ width of margin), in 7 out of 22 cases with marginal margins (less than $2 \mathrm{~cm}$ ), and in 13 out of 18 cases with intralesional surgery. Multivariate evaluation confirmed that the surgical margin remained an independent significant predictor for risk for recurrence. Patients with R0 surgery showed a longer time to peritoneal recurrence and better recurrence-free and disease-specific survival as compared to those with R1 resection. One study based on the analysis of data from the prospective clinical trials ACOSOG Z9000 and Z9002 concluded that tumor size and not a microscopically tumor-positive margin was associated with disease-specific survival [24]. DeMatteo et al. [27] suggested that treatment failure, particularly in large, high-risk GIST, occurs independently of the microscopic margins of resection. In GIST, which some-
Table 1. Major series evaluating the effect of microscopic positive resection of relapse-free survival after resection of primary gastrointestinal stromal tumors (GIST)

\begin{tabular}{|c|c|c|}
\hline Authors & $\begin{array}{l}\text { Number of cases } \\
\text { R0/R1/R2 }\end{array}$ & Influence of R1 resection on RFS \\
\hline $\begin{array}{r}\text { Rutkowski } \\
\text { et al. [2] }\end{array}$ & $\begin{array}{l}\mathrm{R} 0-75.5 \% \\
\mathrm{R} 1 \text { (including } \\
\text { tumor rupture) - } \\
22.4 \%\end{array}$ & $\begin{array}{l}\text { statistically significant in univariate } \\
\text { and multivariate analysis } \\
5 \text {-year DFS rates } 40.5 \text { vs. } 29.5 \% \\
\text { for R0 and R1, respectively }\end{array}$ \\
\hline $\begin{array}{l}\text { Singer } \\
\text { et al. [26] }\end{array}$ & $\begin{array}{l}\mathrm{N}-48 \\
\mathrm{R} 0-62.5 \% \\
\mathrm{R} 1-12.5 \% \\
\mathrm{R} 3-25 \%\end{array}$ & $\begin{array}{l}\text { 5-year RFS for R0: } 76 \text { vs. } 15 \% \\
\text { for R1/R2 }\end{array}$ \\
\hline $\begin{array}{l}\text { McCarter } \\
\text { et al. [24] }\end{array}$ & $\begin{array}{l}\mathrm{N}-819 \\
\mathrm{R} 0-91.1 \% \\
\mathrm{R} 1-8.8 \%\end{array}$ & $\begin{array}{l}\text { no significant difference in RFS for } \\
\text { patients undergoing an R1 vs. R0 } \\
\text { resection of GIST with (HR } 1.095 \text {, } \\
\mathrm{p}=0.73 \text { ) or without (HR } 1.51 \text {, } \\
\mathrm{p}=0.24 \text { ) adjuvant imatinib }\end{array}$ \\
\hline $\begin{array}{l}\text { Gouveia } \\
\text { et al. [25] }\end{array}$ & $\begin{array}{l}\text { R0 - } 78 \text { cases } \\
\text { R1 - } 18 \text { cases }\end{array}$ & $\begin{array}{l}\text { recurrence rate: } 9.0(\mathrm{R} 0) \text { vs. } 27.8 \% \\
(\mathrm{R} 1) \text {; RFS showed a trend to be } \\
\text { shorter after } \mathrm{R} 1 \text { resection } \\
(\mathrm{HR}=3.03 ; \mathrm{p}=0.059) .\end{array}$ \\
\hline
\end{tabular}

DFS = Disease-free survival; HR = hazard ratio; RFS = relapse-free survival

times extend through the serosa of the bowel or stomach wall, cells may be intraperitoneally bashed from the tumor surface, and this may be related to the mechanism of disease recurrence in the form of intra-abdominal and not local recurrences. Crosby et al. [35] reported that in 10 out of 24 patients with negative microscopic margins in primary resection of small bowel GIST and negative lateral margins, peritoneal metastases were detected, which may support this theory. In a systematic review and meta-analysis evaluating the prognostic role of microscopically positive margins for primary GIST [36], which was based on 12 studies comprising 1,985 patients, it was concluded that a microscopically positive margin may have significant impact on disease-free survival (HR (hazard ratio) 1.6; $\mathrm{p}=0.09$ ) without influence on overall survival (HR 1.4).

All available data indicate unequivocally that an important, negative factor influencing the recurrences is tumor perforation or intraperitoneal bleeding $[9,11,37-39]$. Tumor rupture - spontaneous or iatrogenic - may change GIST from low-risk to high-risk or micro-metastatic. In the study performed by the authors' present group [2], the estimated 5-year relapse-free survival rate was only $17 \%$ in the group of patients with ruptured tumor as compared to $55 \%$ in the rest of the patients ( $\mathrm{p}<0.00001)$, and it was a statistically significant independent prognostic factor. The postoperative course of patients with tumor rupture either preoperatively or during resection was similar to that of patients with macroscopic incomplete R2 resection, with shorter overall survival. In the study by McCarter et al. [24], the risk of recurrence within the R1 group appeared to be driven largely by the presence of tumor rupture or intraperitoneal bleeding. The 3-year relapse-free survival for R1 
patients with tumor rupture was 60 versus $80 \%$ in R1 patients without rupture. Excluding all patients with documented tumor rupture resulted in the same outcomes for R1 and R0 patients. Hølmebakk et al. [39] tried to further define the clinical significance of tumor perforation and they reported that recurrence rates after primary tumor resection were increased after major tumor ruptures defined as tumor spillage, tumor fracture or piecemeal resection, bowel perforation at the tumor site, blood-tinged ascites, microscopic tumor infiltration into an adjacent organ, and open surgical biopsy, but not after minor tumor perforations (peritoneal tumor penetration, iatrogenic peritoneal laceration, and microscopically involved margins).

\section{Influence of Perioperative Therapy}

Historically, surgery was the only effective therapy in primary GIST. Taking into account that therapy with tyrosine kinase inhibitors is highly efficient in metastatic GIST, locally advanced GIST may also potentially benefit from neoadjuvant treatment with imatinib through a decrease in size and vulnerability [40-42]. Preoperative therapy devitalizes tumor facilitating tumor resection leading to less morbidity and such strategy is supported by ESMO and NCCN recommendations. According to some studies, the risk of intraperitoneal bleeding/tumor perforation may be decreased after neoadjuvant imatinib in high-risk tumors [41, 43], enabling complete resection, increasing integrity of pseudocapsule, improving quality of margins, and increasing chances for relapse-free survival.

Currently, after resection of GIST considered at high risk of relapse, 36 months of adjuvant treatment with imatinib is the standard therapeutic approach. It seems that this strategy could attenuate the risk of recurrence for primary GIST after R1 resection. The results of a meta-analysis indicated that adjuvant imatinib therapy can decrease the risk of recurrence in primary GIST after R1 resection (HR 1.3), and in the group of patients after R1 resection with- out adjuvant therapy disease-free survival remained poorer [36] Nevertheless, according to the analysis of databases of two adjuvant trials, i.e. SSG XVIII and ACOSOG Z9001, tumor rupture remains significant for unfavorable recurrence-free survival in population of GIST patients treated with adjuvant imatinib [44].

\section{Conclusions}

To summarize, radical surgical excision of primary localized GIST is the standard of care. The published series underline that resection with microscopically negative margins increases the chances for better relapse-free survival, although this effect in lowrisk tumors is uncertain as is the influence on overall survival. In case of primary resection with positive margins by histopathological assessment, a careful reevaluation should be undertaken by an experienced pathologist to exclude false-positive results, and the decision about possible reoperation should be individualized, taking into account a balance between the risk of reoperation, the possible benefits, and the aggressiveness of the primary tumor. Intraperitoneal tumor rupture has the most significant consequences, and shifting primary curable GIST to high-risk or micro-metastatic disease and iatrogenic perforation should always be avoided. Neoadjuvant imatinib therapy in selected cases may facilitate $\mathrm{R} 0$ resection and render the tumor less fragile and hypervascular, decreasing the risk of tumor rupture or intraoperative bleeding. The available data indicate that adjuvant imatinib treatment in GIST is effective in alleviating the effect of R1 primary tumor resection.

\section{Disclosure Statement}

Piotr Rutkowski has received honoraria for lectures from Novartis, Pfizer, BMS, MSD and Roche, and he has served as member of Advisory Board for Novartis, MSD, BMS, Eli Lilly, Amgen and Blueprint Medicines. J. Skoczylas and P. Wisniewski have not declared any conflicts of interest.

\section{References}

1 Miettinen M, Furlong M, Sarlomo-Rikala M, Burke A Sobin LH, Lasota J: Gastrointestinal stromal tumors, intramural leiomyomas, and leiomyosarcomas in the rectum and anus: a clinicopathologic, immunohistochemical, and molecular genetic study of 144 cases. Am J Surg Pathol 2001;25:1121-1133.

2 Rutkowski P, Nowecki ZI, Michej W, et al: Risk criteria and prognostic factors for predicting recurrences after resection of primary gastrointestinal stromal tumor. Ann Surg Oncol 2007;14:2018-2027.

3 Rutkowski P, Hompes D: Combined therapy of gastrointestinal stromal tumors. Surg Oncol Clin N Am 2016;25:735-759.
4 Miettinen M, Kopczynski J, Makhlouf HR, SarlomoRikala M, Gyorffy H, Burke A, Sobin LH, Lasota J: Gastrointestinal stromal tumors, intramural leiomyomas, and leiomyosarcomas in the duodenum: a clinicopathologic, immunohistochemical, and molecular genetic study of 167 cases. Am J Surg Pathol 2003;27: 625-641.

5 Miettinen M, Lasota J, Sobin LH: Gastrointestinal stromal tumors of the stomach in children and young adults: a clinicopathologic, immunohistochemical, and molecular genetic study of 44 cases with long-term follow-up and review of the literature. Am J Surg Pathol 2005;29:1373-1381.
Miettinen M, Makhlouf H, Sobin LH, Lasota J: Gastrointestinal stromal tumors of the jejunum and ileum: a clinicopathologic, immunohistochemical, and molecular genetic study of 906 cases before imatinib with long-term follow-up. Am J Surg Pathol 2006;30:477489.

7 Miettinen M, Lasota J: Gastrointestinal stromal tumors: pathology and prognosis at different sites. Semin Diagn Pathol 2006;23:70-83.

8 Edge SB, Compton CC: The American Joint Committee on Cancer: the 7th edition of the AJCC cancer staging manual and the future of TNM. Ann Surg Oncol 2010;17:1471-1474. 
9 Rutkowski P, Bylina E, Wozniak A, et al: Validation of the Joensuu risk criteria for primary resectable gastrointestinal stromal tumour - the impact of tumour rupture on patient outcomes. Eur J Surg Oncol 2011;37: 890-896.

10 Joensuu H: Risk stratification of patients diagnosed with gastrointestinal stromal tumor. Hum Pathol 2008; 39:1411-1419.

11 Joensuu H, Vehtari A, Riihimäki J, et al: Risk of recurrence of gastrointestinal stromal tumour after surgery: an analysis of pooled population-based cohorts. Lancet Oncol 2012;13:265-274.

12 Pierie JP, Choudry U, Muzikansky A, Yeap BY, Souba WW, Ott MJ: The effect of surgery and grade on outcome of gastrointestinal stromal tumors. Arch Surg 2001;136:383-389.

13 Kim SG: Interpretation of pathologic margin after endoscopic resection of gastrointestinal stromal tumor. Clin Endosc 2016;49:229-231.

14 The ESMO/European Sarcoma Network Working Group: Gastrointestinal stromal tumours: ESMO Clinical Practice Guidelines for diagnosis, treatment and follow-up. Ann Oncol 2014;25:iii21-26.

15 Everett M, Gutman H: Surgical management of gastrointestinal stromal tumors: analysis of outcome with respect to surgical margins and technique. J Surg Oncol 2008;98:588-593.

- 16 Nishimura J, Nakajima K, Omori T, Takahashi T, Nishitani A, Ito T, Nishida T: Surgical strategy for gastric gastrointestinal stromal tumors: laparoscopic vs. open resection. Surg Endosc 2007;21:875-878.

17 Perez EA, Gutierrez JC, Jin X, Lee DJ, Rocha-Lima C, Livingstone AS, Franceschi D, Koniaris LG: Surgical outcomes of gastrointestinal sarcoma including gastrointestinal stromal tumors: a population-based examination. J Gastrointest Surg 2007;11:114-125.

18 Iwahashi M, Takifuji K, Ojima T, et al: Surgical management of small gastrointestinal stromal tumors of the stomach. World J Surg 2006;30:28-35.

19 Koh YX, Chok AY, Zheng HL, Tan CS, Chow PK, Wong WK, Goh BK: A systematic review and metaanalysis comparing laparoscopic versus open gastric resections for gastrointestinal stromal tumors of the stomach. Ann Surg Oncol 2013;20:3549-3560.

20 Xiong H, Wang J, Jia Y, Ye C, Lu Y, Chen C, Shen J, Chen Y, Zhao W, Wang L, Zhou J: Laparoscopic surgery versus open resection in patients with gastrointestinal stromal tumors: an updated systematic review and meta-analysis. Am J Surg 2017;214:538-546.
21 Chi JL, Xu M, Zhang MR, Li Y, Zhou ZG: Laparoscopic versus open resection for gastric gastrointestinal stromal tumors (GISTs): a size-location-matched casecontrol study. World J Surg 2017;41:2345-2352.

$22 \mathrm{Hu}$ J, Or BHN, Hu K, Wang ML: Comparison of the post-operative outcomes and survival of laparoscopic versus open resections for gastric gastrointestinal stromal tumors: a multi-center prospective cohort study. Int J Surg 2016;33:65-71.

23 Joo MK, Park JJ, Kim H, Koh JS, Lee BJ, Chun HJ, Lee SW, Jang YJ, Mok YJ, Bak YT: Endoscopic versus surgical resection of GI stromal tumors in the upper GI tract. Gastrointest Endosc 2016;83:318-326.

24 McCarter MD, Antonescu CR, Ballman KV, et al: Microscopically positive margins for primary gastrointestinal stromal tumors: analysis of risk factors and tumor recurrence. J Am Coll Surg 2012;215:53-59.

25 Gouveia AM, Pimenta AP, Capelinha AF, de la Cruz D, Silva P, Lopes JM: Surgical margin status and prognosis of gastrointestinal stromal tumor. World J Surg 2008;32:2375-2382.

26 Singer S, Rubin BP, Lux ML, Chen CJ, Demetri GD, Fletcher CD, Fletcher JA: Prognostic value of KIT mutation type, mitotic activity, and histologic subtype in gastrointestinal stromal tumors. J Clin Oncol 2002;20: 3898-3905.

27 DeMatteo RP, Lewis JJ, Leung D, Mudan SS, Woodruff JM, Brennan MF: Two hundred gastrointestinal stromal tumors: recurrence patterns and prognostic factors for survival. Ann Surg 2000;231:51-58.

28 Kim MY, Park YS, Choi KD, et al: Predictors of recurrence after resection of small gastric gastrointestinal stromal tumors of $5 \mathrm{~cm}$ or less. J Clin Gastroenterol 2012;46:130-137.

29 Wu TJ, Lee LY, Yeh CN, Wu PY, Chao TC, Hwang TL, Jan YY, Chen MF: Surgical treatment and prognostic analysis for gastrointestinal stromal tumors (GISTs) of the small intestine: before the era of imatinib mesylate. BMC Gastroenterol 2006;6:29.

30 Bucher P, Egger JF, Gervaz P, Ris F, Weintraub D, Villiger P, Buhler LH, Morel P: An audit of surgical management of gastrointestinal stromal tumours (GIST). Eur J Surg Oncol 2006;32:310-314.

31 Langer C, Gunawan B, Schüler P, Huber W, Füzesi L, Becker $\mathrm{H}$ : Prognostic factors influencing surgical management and outcome of gastrointestinal stromal tumours. Br J Surg 2003;90:332-339.

32 Aparicio T, Boige V, Sabourin JC, Crenn P, Ducreux M, Le Cesne A, Bonvalot S: Prognostic factors after surgery of primary resectable gastrointestinal stromal tumours. Eur J Surg Oncol 2004;30:1098-1103.
33 Åhlén J, Karlsson F, Wejde J, Nilsson IL, Larsson C, Bränström R: Wide surgical margin improves the outcome for patients with gastrointestinal stromal tumors (GISTs). World J Surg 2018;42:2512-2521.

34 Lin SC, Huang MJ, Zeng CY, Wang TI, Liu ZL, Shiay RK: Clinical manifestations and prognostic factors in patients with gastrointestinal stromal tumors. World J Gastroenterol 2003;9:2809-2812.

35 Crosby JA, Catton CN, Davis A, Couture J, O’Sullivan B, Kandel R, Swallow CJ: Malignant gastrointestinal stromal tumors of the small intestine: a review of 50 cases from a prospective database. Ann Surg Oncol 2001;8:50-59.

36 Zhi X, Jiang B, Yu J, Røe OD, Qin J, Ni Q, Sun L, Xu M, Zhu J, Ma L: Prognostic role of microscopically positive margins for primary gastrointestinal stromal tumors: a systematic review and meta-analysis. Sci Rep 2016;6:21541.

37 Hohenberger P, Ronellenfitsch U, Oladeji O, Pink D, Ströbel P, Wardelmann E, Reichardt P: Pattern of recurrence in patients with ruptured primary gastrointestinal stromal tumour. Br J Surg 2010;97:1854-1859.

38 Peparini N, Chirletti P: Tumor rupture during surgery for gastrointestinal stromal tumors: pay attention! World J Gastroenterol 2013;19:2009-2010.

39 Hølmebakk T, Bjerkehagen B, Boye K, Bruland $\varnothing$, Stoldt S, Hall KS: Definition and clinical significance of tumour rupture in gastrointestinal stromal tumours of the small intestine. Br J Surg 2016;103:684-691.

40 Rutkowski P, Gronchi A, Hohenberger P, et al: Neoadjuvant imatinib in locally advanced gastrointestinal stromal tumors (GIST): the EORTC STBSG experience. Ann Surg Oncol 2013;20:2937-2943.

41 Tielen R, Verhoef C, van Coevorden F, Gelderblom H, Sleijfer S, Hartgrink HH, Bonenkamp JJ, van der Graaf WT, de Wilt JH: Surgical treatment of locally advanced, non-metastatic, gastrointestinal stromal tumours after treatment with imatinib. Eur J Surg Oncol 2013;39:150-155.

42 Ford SJ, Gronchi A: Indications for surgery in advanced/metastatic GIST. Eur J Cancer 2016;63:154167.

43 Tang S, Yin Y, Shen C, Chen J, Yin X, Zhang B, Yao Y, Yang J, Chen Z: Preoperative imatinib mesylate (IM) for huge gastrointestinal stromal tumors (GIST). World J Surg Oncol 2017;15:79.

44 Joensuu H, Eriksson M, Hall KS, et al: Risk factors for gastrointestinal stromal tumor recurrence in patients treated with adjuvant imatinib. Cancer 2014;120:23252333. 